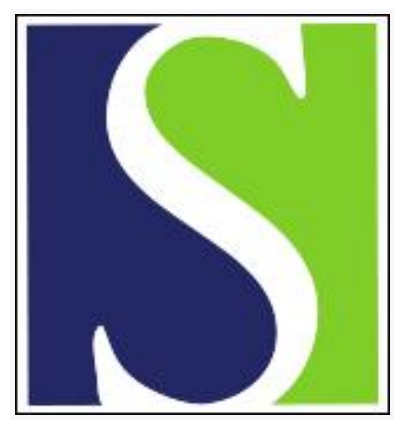

Scand J Work Environ Health 2014;40(6):631-638

https://doi.org/10.5271/sjweh.3453

Published online: 10 Sep 2014, Issue date: 01 Nov 2014

Unnecessary work tasks and mental health: a prospective analysis of Danish human service workers

by Madsen IEH, Tripathi M, Borritz M, Rugulies R

This study finds that unnecessary work tasks are associated with decreased mental health both cross-sectionally and prospectively, after adjusting for baseline mental health. This association was stronger for older participants and those with poor baseline mental health. These findings indicate that eliminating work tasks that are experienced as unnecessary may be beneficial for employee mental health.

Affiliation: National Research Centre for the Working Environment, Lerso Parkalle 105, DK-2100 Copenhagen, Denmark. inm@nrcwe.dk

Refers to the following texts of the Journal: 2006;32(6):443-462 2013;39(3):310-318

The following articles refer to this text: 2015;41(2):216-217; 2015;41(2):218; 2016;42(3):192-200; 2018;44(2):219-223

Key terms: Denmark; human service worker; illegitimate task; mental health; occupational health; psychological distress; stress; unnecessary work task; worker

This article in PubMed: www.ncbi.nlm.nih.gov/pubmed/25205073

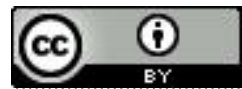




\title{
Unnecessary work tasks and mental health: a prospective analysis of Danish human service workers
}

\author{
by Ida EH Madsen, PhD, ${ }^{1}$ Manisha Tripathi, MSc, ${ }^{1}$ Marianne Borritz, PhD, ${ }^{2}$ Reiner Rugulies, PhD 1, 3,4
}

\begin{abstract}
Madsen IEH, Tripathi M, Borritz M, Rugulies R. Unnecessary work tasks and mental health: a prospective analysis of Danish human service workers. Scand J Work Environ Health. 2014;40(6):631-638. doi:10.5271/sjweh.3453

Objectives According to the "stress-as-offense-to-self" perspective, work tasks that are considered unnecessary or unreasonable - so-called "illegitimate work tasks" - are likely to elicit stress-reactions. Previous studies, mostly cross-sectional, have shown that illegitimate tasks are associated with increased self-reported stress, cortisol, and counterproductive work behavior. In this article, we examine the prospective association between unnecessary work tasks, one type of illegitimate work tasks, and mental health among Danish human service workers. Further, we explore whether this association is modified by sex, age, occupational position, and baseline mental health status.
\end{abstract}

Methods The data were obtained from self-administered questionnaires from 1351 Danish human service workers in three waves of data-collection during 1999-2005. We measured unnecessary work tasks by a single item, and assessed mental health using the 5-item mental health inventory from the Short form 36 questionnaire. We analyzed data using multi-level modeling, adjusting for potential confounding by sex, age, cohabitation, occupational position, and baseline mental health.

Results Unnecessary work tasks were prospectively associated with a decreased level of mental health. This association was stronger for employees with poor baseline mental health and tended to be more pronounced among older employees. Among participants with poor baseline mental health, the association was explained by neither psychological demands nor decision latitude.

Conclusions Our findings suggest that the prevention of unnecessary work tasks may benefit employee mental health, particularly among employees with pre-existing mental health problems.

Key terms illegitimate task; occupational health; psychological distress; stress.

Mental disorders are a leading cause of morbidity and disability across the world (1). In addition to substantial individual consequences in terms of quality of life and role impairment (2), mental disorders are associated with considerable societal costs in terms of reduced productivity, sickness absence, and treatment expenses $(3,4)$. According to the World Health Organization, mental health is not only defined by the absence of mental disorder, but is "... a state of well-being in which the individual realizes his or her own abilities, can cope with the normal stresses of life, can work productively and fruitfully, and is able to make a contribution to his or her community" $(5, \mathrm{p} 2)$. Reduced mental health is not only inextricably linked with lowered quality of life (5, $6)$, but also bears economic and societal costs, including substantially increased risk of long-term sickness absence, even at levels well below established clinical cut-off points for mental disorder (7-11)

Previous literature linking the psychosocial work environment with reduced mental health has mainly focused on a relatively limited range of factors, including job strain, effort-reward imbalance, social support, and bullying (12-17). Norbert Semmer et al's "stressas-offense-to-self” framework (18) suggests new condi-

1 National Research Centre for the Working Environment, Copenhagen, Denmark.

2 Occupational Medicine Department, Koge Hospital, Koge, Denmark.

3 Department of Public Health, University of Copenhagen, Copenhagen, Denmark.

4 Department of Psychology, University of Copenhagen, Copenhagen, Denmark.

Correspondence to: Ida E H Madsen, National Research Centre for the Working Environment, Lerso Parkalle 105, DK-2100 Copenhagen, Denmark. [E-mail: ihm@nrcwe.dk] 
tions that may be relevant to employee mental health, including factors that are threatening to the personal or social self-esteem of the employee. According to the theory, an individual's social self-esteem may be threatened by behaviors that directly or indirectly signal disrespect (18). These behaviors include the assignment of what Semmer calls "illegitimate work tasks", tasks that are perceived as offending one's professional identity (19) and considered unreasonable or unnecessary. Whereas unreasonable tasks constitute tasks that the employee feels should be carried out by someone else, unnecessary tasks are tasks that should not be carried out at all. The assignment of either type of illegitimate task, according to the stress-as-offense-to-self perspective, may trigger stress reactions. One example is a nurse spending excessive time on documentation due to incompatible IT systems: if this activity is not considered a part of the core job role for the employee, spending prolonged time on such tasks is likely to be considered stressful (19).

Previous studies have related illegitimate work tasks to decreased well-being (18) and increased levels of stress (20), cortisol (21) and counterproductive work behavior (19). Most studies have, however, used crosssectional designs, and - to the best of our knowledge - no study has yet examined the prospective relations between unnecessary work tasks and mental health. As the theory suggests that illegitimate tasks pose a threat to self-esteem, and self-esteem is central to mental health outcomes such as depression (18), it is likely that this exposure may affect mental health in particular.

This study examines the associations between unnecessary work tasks, which are one type of illegitimate work tasks, and mental health, hypothesizing that an increased level of unnecessary work tasks is prospectively associated with a decreased level of mental health. Further, we test exploratively, whether the association is modified by sex, age, occupational position or baseline mental health. As the experience of work tasks is likely to be affected by the mental health state of the individual, a prospective design controlling for baseline mental health is necessary to avoid circular reasoning. We use data from a cross-occupational sample of Danish human service workers, a cluster of occupational groups in which illegitimate work tasks have received considerable attention during recent years, particularly in relation to documentation considered to be excessive and unnecessary (22-23). This development has occurred in the context of new public management - a series of reforms conducted since the 1980s that introduced market-oriented management strategies to modernize the public sector and make it more efficient (24).

\section{Methods}

\section{Data}

The study was carried out as a secondary data analysis using data from the Project on Burnout, Motivation and Job Satisfaction (PUMA). PUMA was a three-wave, open cohort study designed to examine burnout among service workers. Participants in the PUMA study were recruited from seven human service organizations: (i) 10 social security offices in an urban area; (ii) a state psychiatric prison; (iii) 16 county institutions for severely disabled people; (iv) 3 somatic wards (surgical, medical, gynecological-obstetric) from two county hospitals; (v) a psychiatric ward from a psychiatric hospital; (vi) a homecare service in a rural area; and (vii) a homecare service in an urban area. Data were collected in 1999 2000 (wave 1), 2002-2003 (wave 2), and 2005 (wave 3). The response rates for PUMA ranged between $75-88 \%$ (25). The Danish Data Protection Agency (Datatilsynet) and the Scientific Ethical Committees (Videnskabsetisk Komite) in the respective counties approved PUMA. The questionnaire contained information regarding the purpose of the study, and the submission of the questionnaire was regarded as informed consent. For details on PUMA see Borritz et al (26).

\section{Measurements}

From the self-administered questionnaires we included data on unnecessary work tasks, mental health, cohabitation, and tenure. Unnecessary work tasks were measured by the item "Do you sometimes have to do things in your job which appear to be unnecessary?" with five response categories ranging from "always" to "never/ almost never". For the analyses, due to a low number of respondents indicating always having to do unnecessary tasks, we collapsed the responses always and often.

Mental health was measured by the Mental Health Inventory (MHI-5) a 5-item scale from the Short-Form Health Survey (27). The MHI-5 asks respondents "How much of the time in the past four weeks have you: (i) been very nervous, (ii) felt downhearted, (iii) felt happy, (iv) felt calm and peaceful, and (v) felt so down in the dumps that nothing could cheer you up?" We scored each item of the scale from $0-100$ with higher scores indicating fewer symptoms and calculated a mean score, if participants had data on $\geq 3$ items. Following previous studies (28-30), we defined poor mental health as a mean score of $\leq 52$. Cohabitation was measured by asking the respondent if they lived with a partner or spouse. Tenure was measured by asking how long they had been employed at their workplace.

Furthermore, we included national Danish register data on sex, age, and occupational position $(31,32)$. 
These data were included from the Civil Registration System (31) and the Employment Classification Module (32), which includes data on an individual's most important employment activity throughout each year. Both registers have excellent coverage of the Danish population and are considered to be of high validity for research purposes $(31,32)$. Occupational position was classified as high, intermediate, or low, following the European Socioeconomic Classification (33) based on the International Labor Organization's International Standard Classification of Occupations (34).

Also, to examine if the association between unnecessary work tasks and mental health was independent from effects of more established work environment factors, we included data on psychological job demands and decision latitude at work (35). Psychological job demands were measured by a 3 -item scale, assessing the demands to work fast, time pressure, and conflicting demands. A 4-item scale assessing both skill discretion and decision authority in accordance with the Demand -Control Model (35) was used to measure decision latitude. The items used to measure psychological demands and decision latitude have previously been validated against the Demand-Control Questionnaire (36).

\section{Study population}

There were 1391 individuals who participated in $\geq 2$ consecutive waves of the PUMA study, contributing a total of 2072 observations of both baseline and follow-up data. We excluded 101 observations due to missing data on key variables (unnecessary work tasks, baseline or follow-up mental health, sex, age, cohabitation, occupational position), yielding a total 1971 observations from 1351 individuals. The characteristics of participants are shown in table 1, according to wave of baseline and follow-up data.

\section{Statistical analysis}

We examined the association between unnecessary work tasks and mean mental health level prospectively, adjusting for baseline mental health level. We applied multilevel modeling using either wave 1 or 2 as baseline and the subsequent wave as follow-up. We considered this strategy reasonable as the length of follow-up between waves 1 and 2 (median follow-up: 2.9 years) was similar to the length between waves 2 and 3 (median follow-up: 2.6 years).

All models controlled for sex, age, cohabitation and occupational position, as these factors have been related to mental health (37-39) and might be related to the level of unnecessary work tasks. We also adjusted for baseline values of mental health as we considered it likely that the experience of viewing work tasks as unnecessary could be affected by this factor. We furthermore examined whether the association was modified by sex, age, occupational position, or poor baseline mental health by including two-way interaction terms for each potential effect modifier in the model. We included the listed factors as we considered them potential vulnerability factors that could render individuals more susceptible to any effects of unnecessary work tasks. As we found a tendency towards interaction with age $(\mathrm{P}<0.10)$, we further examined whether this interaction was due to tenure, by adjusting for workplace tenure. Additionally, we examined whether the association between unnecessary work tasks and mental health was independent from job demands and control by adjusting for these factors.

Analyses were conducted in SAS version 9.3 (SAS Institute, Cary, NC, USA), using the procedure mixed, and figures were plotted in R. We initially specified the models with random effects for person-nested-withinworkplace to account for data clustering at the levels of individuals and workplaces. When adjusting for baseline mental health, though, there was no additional effect of the person-level indicator and this parameter was left out of the analyses. We specified a random-effect interaction between the exposure and the workplace, allowing the exposure effect to vary between workplaces. This method theoretically increases the generalizability of the results, beyond those workplaces included in the study, to the background population from which they were sampled (40). We inserted the exposure "unnecessary work tasks" as a categorical predictor to not assume linearity between exposure and outcome.

\section{Results}

Unnecessary work tasks were prospectively associated with mental health, after adjusting for the baseline mental health (see table 2). The relation between unnecessary work tasks and mean mental health level appeared curvilinear, with stronger effects at the higher levels of unnecessary work tasks.

We found no indication of effect-modification by sex or occupational position. There was, however, a statistically significant interaction between unnecessary work tasks and poor baseline mental $(\mathrm{P}<0.001)$. The stratified analyses revealed that the association between unnecessary work tasks and mental health was stronger among individuals with poor baseline mental health compared to other participants (see figure 1).

For participants with poor mental health at baseline, the $b$ associated with the highest level of unnecessary work tasks was -17.3. For participants with good mental health at baseline this effect was only -2.8 and was statistically non-significant. 
Table 1. Characteristics of the study population [SD=standard deviation]

\begin{tabular}{|c|c|c|c|c|c|c|c|c|}
\hline & \multicolumn{4}{|c|}{ Wave 1-2 participants } & \multicolumn{4}{|c|}{ Wave 2-3 participants } \\
\hline & $\mathrm{N}$ & $\%$ & Mean & SD & $\mathrm{N}$ & $\%$ & Mean & SD \\
\hline $\mathrm{N}$ total & 981 & 100 & & & 990 & 100 & & \\
\hline Age & & & 44.4 & 8.7 & & & 44.9 & 9.2 \\
\hline Women & 815 & 83 & & & 834 & 84 & & \\
\hline Cohabiting & 806 & 82 & & & 797 & 81 & & \\
\hline \multicolumn{9}{|l|}{ Unnecessary work tasks } \\
\hline Always/often & 122 & 12 & & & 154 & 16 & & \\
\hline Sometimes & 402 & 41 & & & 401 & 41 & & \\
\hline Seldomly & 337 & 34 & & & 340 & 34 & & \\
\hline Never/almost never & 120 & 12 & & & 95 & 10 & & \\
\hline \multicolumn{9}{|l|}{ Occupational position } \\
\hline High & 271 & 28 & & & 281 & 28 & & \\
\hline Intermediate & 315 & 32 & & & 343 & 35 & & \\
\hline Low & 395 & 40 & & & 366 & 37 & & \\
\hline Poor mental health, baseline & 62 & 6 & & & 86 & 9 & & \\
\hline Mental health level, baseline & & & 79.5 & 14.3 & & & 77.9 & 15.3 \\
\hline Mental health level, follow up & & & 76.9 & 16.0 & & & 76.6 & 16.2 \\
\hline
\end{tabular}

Table 2. Unnecessary work tasks at baseline and mental health at follow-up [95\% Cl=95\% confidence interval]

\begin{tabular}{lrcrr}
\hline & \multicolumn{3}{c}{ Mental health } & $\begin{array}{c}\text { P-value, } \\
\text { type 3 test }\end{array}$ \\
\cline { 2 - 4 } & Mean & $95 \% \mathrm{Cl}$ & $b$ & \\
\cline { 2 - 4 } Unnecessary work tasks & & & & 0.0038 \\
Always/often & $74.00^{\mathrm{a}}$ & $72.22-75.78$ & $-4.20^{\mathrm{a}}$ & \\
Sometimes & $76.00^{\mathrm{a}}$ & $74.75-77.26$ & $-2.19^{\mathrm{a}}$ & \\
Seldomly & 77.47 & $76.11-78.84$ & $-0.73^{\mathrm{a}}$ & \\
Never/almost never & 78.20 & $76.10-80.29$ & Reference &
\end{tabular}

a Estimates are adjusted for sex, age, cohabitation, occupational position, and baseline mental health score.

a $\mathrm{P}<0.001$.

We also observed a tendency towards an interaction with age $(\mathrm{P}<0.10)$. As shown in figure 2 , the association between unnecessary work tasks and mental health tended to be slightly stronger among older compared to younger employees. For participants aged $\geq 45$ years, the $b$ associated with the highest level of unnecessary work tasks was -5.7 , whereas it was -4.10 and -1.97 , respectively, for participants aged $35-44$ and $<35$ years. To examine whether this tendency was explained by exposure length, we further adjusted for tenure, but this factor did not explain the tendency towards effect modification, and there was no statistically significant three-way interaction between unnecessary work tasks, age and tenure.

When adjusting for baseline job demands and control, the prospective association between unnecessary work tasks and mental health attenuated somewhat in the main effects analysis and became statistically insignificant. However, the interaction with poor baseline mental health remained, and for participants with poor baseline mental health there was still a similar asso- ciation between unnecessary work tasks and decreased mental health, with a $b$ of -15.2 for the participants with the highest level of unnecessary work tasks.

\section{Discussion}

We found that unnecessary work tasks were prospectively associated with decreased mental health, after adjusting for baseline mental health. This association was stronger for those with poor baseline mental health and tended to be more pronounced among older compared to younger participants. Also, the association was independent of the psychological demands and decision latitude at work, within the group with poor baseline mental health. This finding is in line with a previous study on counterproductive work behavior (19), which found that illegitimate tasks were associated with increased levels of behaviors such as taking overly long breaks, stealing or gossiping about other members of the organization. This association was independent of effort-reward imbalance at work and organizational justice. Together, these findings suggest that the stressas-offense-to-self perspective may add information regarding the psychosocial work environment, which is not included in existing work stress models. However, given the attenuation of the main-effects association in the present analyses when adjusting for demands and control, further research is needed to clarify the extent to which unnecessary work tasks may lead to reduced mental health, for whom, and in what contexts.

We found that the association between unnecessary work tasks and mental health was most pronounced among individuals with poor mental health at baseline. 


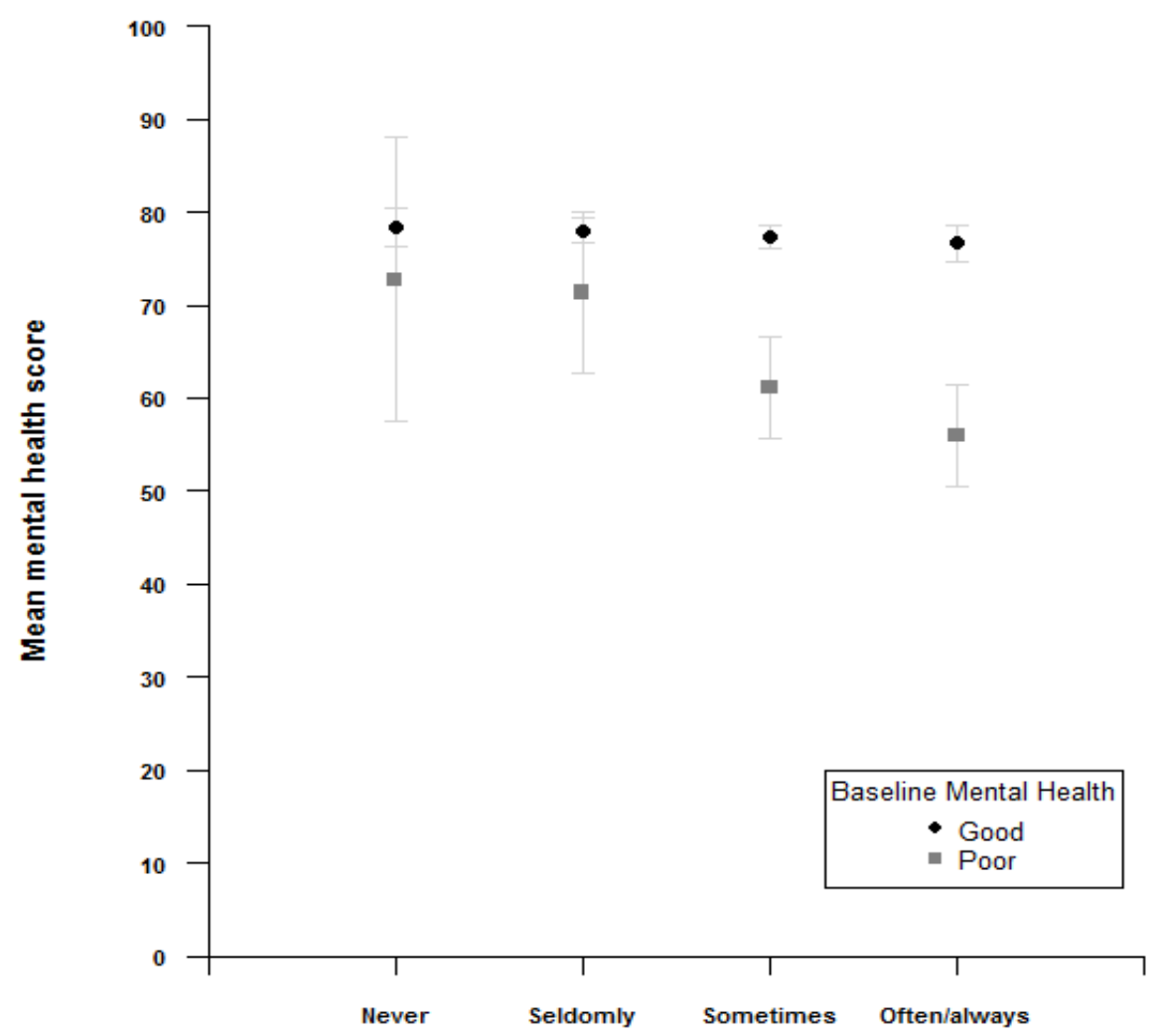

Figure 1. Mental health in relation to unnecessary work tasks (prospective analysis), stratified by baseline mental health status.

\section{Unnecessary work tasks}

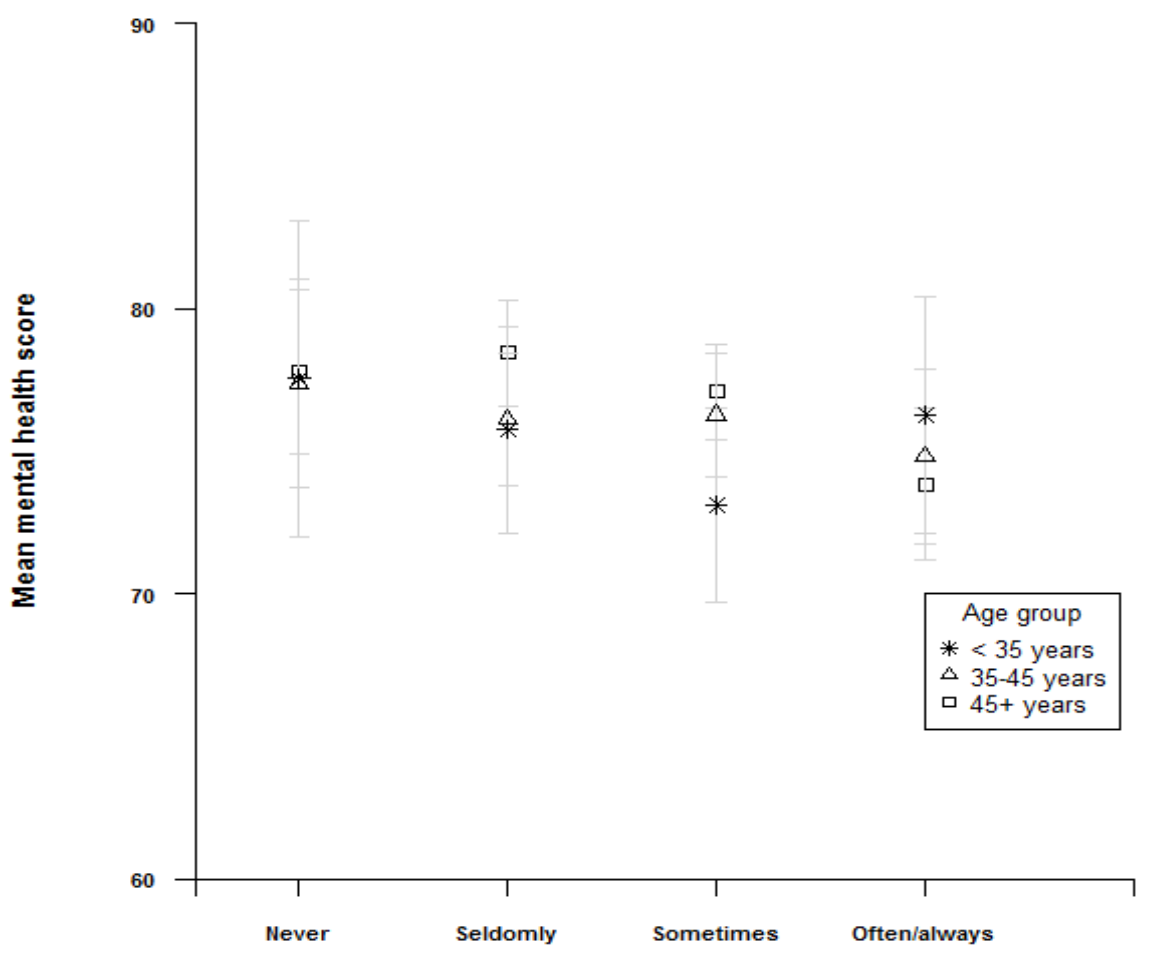

Unnecessary work tasks

Figure 2. Mental health in relation to unnecessary work tasks (prospective analysis), stratified by age. 
This finding is in line with a study by Kottwitz et al (21), which found that illegitimate tasks were associated with increased cortisol levels among male employees with poor self-rated health but not employees with medium or good self-rated health. The effect-modification by baseline health status may be related to psychological processes that render the individual more vulnerable to the effects of illegitimate tasks. Such processes may involve self-esteem, which is thought to be central to the development of depression (41-43). It is likely that individuals with poor self-esteem are more vulnerable to threats to their social esteem, of which unnecessary work tasks constitute an example.

We also found a tendency towards a slightly stronger association between unnecessary work tasks and mental health among older compared to younger employees. This tendency was not explained by job tenure, suggesting that the underlying factor was not the duration of exposure. It is possible that age in this context acts as a status indicator and that employee expectations regarding the performance of unnecessary tasks differ according to age. This might explain why older employees possibly experience the performance of unnecessary tasks as more offensive to the self, and consequently more detrimental to their mental health. The direction of such effect modification was, however, not hypothesized before analyzing the data and the result should be interpreted as hypothesis-generating rather than confirmatory.

It is central to the concept of illegitimate tasks that the legitimacy of the work tasks is subjectively experienced and linked closely with the professional role identity of the employee. Work tasks are unlikely to be experienced as illegitimate if they are in line with or affirm the core role of the employee - in this context the same tasks are likely to be interpreted as "part of the job" (18). Consequently, the evaluation of the necessity of work tasks, and their legitimacy, likely varies across organizational levels. It also seems unlikely that work tasks would be assigned were they not considered necessary from some perspective. The process of eliminating unnecessary work tasks, then, is likely to be twodimensional: First, eliminating tasks that are actually considered unnecessary throughout the organization, and second, working towards a mutual understanding of the necessity of work tasks across organizational levels. Further research to identify specific interventions that may reduce the levels of unnecessary work tasks in different organizational contexts seems warranted.

\section{Strengths and limitations}

The strengths of this study include the prospective design, the adjustment for baseline mental health, and the relatively large dataset that allowed analyses of effect modification. To the best of our knowledge, this is the first study that has prospectively examined the association of illegitimate tasks and mental health. These strengths should be weighted against the limitations of the study. First, we measured the exposure of unnecessary work tasks with a single item and could not assess unreasonable work tasks. Because this study was a secondary data analysis, we chose the exposure measurement from the data available. However, the single-item measurement may have decreased the precision of the analyses and increased random error (44). Further, the item phrasing includes an indication of frequency ("do you sometimes have to do...") that does not correspond well to all response categories (eg, "seldom"). This may have confused some respondents and decreased the measurement reliability.

Second, we measured both exposures and outcomes by self-report. Such analyses may raise concerns of common method variance inflating the associations (45, 46). Although we addressed such bias by conducting prospective analyses accounting for baseline mental health (45), concerns regarding common method variance remain a valid limitation of this study. However, it should be noted that, because the experience of unnecessary work tasks is linked with the professional identity of the employee, it is the subjective experience that is of main interest rather than an objective assessment of whether or not the work tasks in question are necessary. Also, no fully objective assessments of mental health exist, as even expert ratings are based partly on the reporting of the individual. Consequently, it does not seem feasible to examine the relation between unnecessary work tasks and mental health without relying on self-reported data.

Finally, the study population consisted of employees in human service organizations primarily within the public sector. This may decrease the generalizability of the findings to organizations outside this field. As most research on illegitimate tasks has focused on publicsector employees, future research on this issue outside the public sector context seems warranted.

\section{Concluding remarks}

Our findings suggest that the elimination of unnecessary work tasks may be beneficial for employee mental health, particularly among employees with pre-existing poor mental health. Such interventions could target the elimination of tasks that are experienced as unnecessary throughout the organization and the achievement of a joint understanding of the necessity of tasks that are experienced as unnecessary only at some organizational levels. 


\section{Acknowledgments}

The Danish Working Environment Research Fund supported this work under grant number 9-2011-03.

\section{References}

1. Whiteford HA, Degenhardt L, Rehm J, Baxter AJ, Ferrari AJ, Erskine HE, et al. Global burden of disease attributable to mental and substance use disorders: findings from the Global Burden of Disease Study 2010. Lancet. 2013;382:1575-86. http://dx.doi.org/10.1016/S0140-6736(13)61611-6.

2. Druss BG, Hwang I, Petukhova M, Sampson NA, Wang PS, Kessler RC. Impairment in role functioning in mental and chronic medical disorders in the United States: results from the National Comorbidity Survey Replication. Mol Psychiatry. 2008;14:728-37. http://dx.doi.org/10.1038/mp.2008.13.

3. Simon GE, Barber C, Birnbaum HG, Frank RG, Greenberg PE, Rose RM, et al. Depression and work productivity: the comparative costs of treatment versus nontreatment. J Occup Environ Med. 2001;43:2-9. http://dx.doi. org/10.1097/00043764-200101000-00002.

4. Kessler RC. The Costs of Depression. Psychiatr Clin North Am. 2012;35:1-14. http://dx.doi.org/10.1016/j. psc.2011.11.005.

5. Herrman H, Saxena S, Moodie R, Walker L. Introduction: Promoting Mental Health as a Public Health Priority. In: Herrman H, Saxena S, Moodie R, editors. Promoting mental health: concepts, emerging evidence, practice : report of the World Health Organization, Department of Mental Health and Substance Abuse in collaboration with the Victorian Health Promotion Foundation and the University of Melbourne. Geneva: World Health Organization; 2005. p. 2-17.

6. Bowling A. Health-related quality of life: conceptual meaning, use and measurement. In. Measuring disease - A review of disease-specific quality of life measurement scales. Buckingham: Open University Press; 2001. p. 1-19.

7. Hjarsbech PU, Andersen RV, Christensen KB, Aust B, Borg $\mathrm{V}$, Rugulies R. Clinical and non-clinical depressive symptoms and risk of long-term sickness absence among female employees in the Danish eldercare sector. J Affect Disord. 2011;87-93. http://dx.doi.org/10.1016/j.jad.2010.07.033.

8. Thielen K, Nygaard E, Andersen I, Diderichsen F. Employment consequences of depressive symptoms and work demands individually and combined. Eur J Public Health. 2014 Feb;24(1):34-9. http://dx.doi.org/10.1093/eurpub/ckt011.

9. Terluin B, Rhenen W, Anema J, Taris T. Psychological symptoms and subsequent sickness absence. Int Arch Occup Environ Health. 2011;84:825-37. http://dx.doi.org/10.1007/ s00420-011-0637-4.

10. McTernan WP, Dollard MF, LaMontagne AD. Depression in the workplace: An economic cost analysis of depressionrelated productivity loss attributable to job strain and bullying. Work Stress. 2013;27:321-38. http://dx.doi.org/10.1080/026
78373.2013.846948.

11. Thorsen S, Rugulies R, Hjarsbech P, Bjorner J. The predictive value of mental health for long-term sickness absence: the Major Depression Inventory (MDI) and the Mental Health Inventory (MHI-5) compared. BMC Med Res Methodol. 2013;13:115. http://dx.doi.org/10.1186/1471-2288-13-115.

12. Bonde JPE. Psychosocial factors at work and risk of depression: a systematic review of the epidemiological evidence. Occup Environ Med. 2008;65:438-45. http://dx.doi. org/10.1136/oem.2007.038430.

13. Netterstrøm B, Conrad N, Bech P, Fink P, Olsen O, Rugulies $\mathrm{R}$, et al. The relation between work-related psychosocial factors and the development of depression. Epidemiol Rev. 2008;30:118-32. http://dx.doi.org/10.1093/epirev/mxn004.

14. Siegrist J. Chronic psychosocial stress at work and risk of depression: evidence from prospective studies. Eur Arch Psychiatry Clin Neurosci. 2008;258:115-9. http://dx.doi. org/10.1007/s00406-008-5024-0.

15. Nieuwenhuijsen K, Bruinvels D, Frings-Dresen M. Psychosocial work environment and stress-related disorders, a systematic review. Occ Med. 2010;60:277-86. http://dx.doi. org/10.1093/occmed/kqq081.

16. Stansfeld S, Candy B. Psychosocial work environment and mental health--a meta-analytic review. Scand J Work Environ Health. 2006;32:443-62. http://dx.doi.org/10.5271/ sjweh.1050.

17. Nielsen MB, Einarsen S. Outcomes of exposure to workplace bullying: A meta-analytic review. Work Stress. 2012;26:30932. http://dx.doi.org/10.1080/02678373.2012.734709.

18. Semmer NK, Jacobshagen N, Meier LL, Ellaway A. Occupational stress research: the "stress-as-offense-toself" perspective. In: Houdmont J, McIntyre S, editors. Occupational health psychology - European perspectives on research, education and practice. Nottingham: ISMAI publishers; 2007. p. 43-60.

19. Semmer NK, Tschan F, Meier LL, Facchin S, Jacobshagen N. Illegitimate Tasks and Counterproductive Work Behavior. Appl Psychol. 2010;59:70-96. http://dx.doi.org/10.1111/ j.1464-0597.2009.00416.x.

20. Björk L, Bejerot E, Jacobshagen N, Härenstam A. I shouldn't have to do this: Illegitimate tasks as a stressor in relation to organizational control and resource deficits. Work Stress. 2013;27:262-77. http://dx.doi.org/10.1080/02678373.2013. 818291 .

21. Kottwitz MU, Meier LL, Jacobshagen N, Kälin W, Elfering A, Hennig J, et al. Illegitimate tasks associated with higher cortisol levels among male employees when subjective health is relatively low: an intra-individual analysis. Scand J Work Environ Health. 2013;39:310-8. http://dx.doi.org/10.5271/ sjweh.3334.

22. Poulsen KA. New public management nedbryder den sociale kapital [New public management breaks down the social capital]. Dagens Medicin. 2013; [updated 2013; cited 2014 Sept 3]. Available from: http://www.dagensmedicin.dk/ opinion/debat/new-public-management-nedbryder-densociale-kapital/. 
23. Dandanell N. Finansministeriet antager, at offentligt ansatte er dovne [The Ministry of Finance assumes that all public employees are lazy]. Information. 2014; [updated 2014; cited 2014 Sept 3]. Available from: http://www.information. $\mathrm{dk} / 483943$.

24. Kamp A, Hohnen P, Hviid H, Scheller VK. New public management - konsekvenser for arbejdsmiljø og produktivitet [New public management - consequences for working environment and productivity]. Roskilde: Center for Arbejdslivsforskning, Roskilde University; 2013.

25. Madsen IEH. Social work environment and mental health - an epidemiological study of interpersonal work environment factors as predictors of psychotropic treatment. Copenhagen: National Research Centre for the Working Environment; 2012.

26. Borritz M, Rugulies R, Bjorner JB, Villadsen E, Mikkelsen OA, Kristensen TS. Burnout among employees in human service work: design and baseline findings of the PUMA study. Scand J Public Health. 2006;34:49-58. http://dx.doi. org/10.1080/14034940510032275.

27. Bjorner JB, Thunedborg K, Kristensen TS, Modvig J, Bech P. The Danish SF-36 health survey: translation and preliminary validity studies. J Clin Epidemiol. 1998;51:991-9. http:// dx.doi.org/10.1016/S0895-4356(98)00091-2.

28. Rugulies R, Bültmann U, Aust B, Burr H. Psychosocial work environment and incidence of severe depressive symptoms: Prospective findings from a 5-year follow-up of the Danish Work Environment Cohort Study. Am J Epidemiol. 2006;163:877-87. http://dx.doi.org/10.1093/aje/kwj119.

29. Strand BH, Dalgard OS, Tambs K, Rognerud M. Measuring the mental health status of the Norwegian population: a comparison of the instruments SCL-25, SCL-10, SCL-5 and MHI-5 (SF-36). Nord J Psychiatry. 2003;57:113-8. http:// dx.doi.org/10.1080/08039480310000932.

30. Holmes WC. A short, psychiatric, case-finding measure for HIV seropositive outpatients: Performance characteristics of the 5-item Mental Health Subscale of the SF-20 in a male, seropositive sample. Med Care. 1998;36:237-43. http:// dx.doi.org/10.1097/00005650-199802000-00012.

31. Pedersen CB. The Danish civil registration system. Scand J Public Health. 2011;39:22-5. http://dx.doi. org/10.1177/1403494810387965.

32. Petersson F, Baadsgaard M, Thygesen LC. Danish registers on personal labour market affiliation. Scand J Public Health. 2011;39:95-8. http://dx.doi.org/10.1177/1403494811408483.

33. Matrices and Syntax. Institute for Social \& Economic Research, University of Essex; [updated 2013; cited 2014 Jun 6]. Available from: https://www.iser.essex.ac.uk/archives/ esec/matrices-and-syntax.

34. ISCO-88: Major, Sub-major, minor and unit group titles. International Labour Organization (ILO); [updated 2004; cited 2014 Jun 6]. Available from: http://www.ilo.org/public/ english/bureau/stat/isco/isco88/major.htm.
35. Karasek R, Brisson C, Kawakami N, Houtman I, Bongers P, Amick B. The Job Content Questionnaire (JCQ): an instrument for internationally comparative assessments of psychosocial job characteristics. J Occup Health Psychol. 1998;3:322-55. http://dx.doi.org/10.1037/1076-8998.3.4.322.

36. Fransson E, Nyberg S, Heikkila K, Alfredsson L, Bacquer $\mathrm{DD}$, Batty GD, et al. Comparison of alternative versions of the job demand-control scales in 17 European cohort studies: the IPD-Work consortium. BMC Public Health. 2012;12:62. http://dx.doi.org/10.1186/1471-2458-12-62.

37. Alonso J, Angermeyer MC, Bernert S, Bruffaerts R, Brugha IS, Bryson H, et al. Prevalence of mental disorders in Europe: results from the European Study of the Epidemiology of Mental Disorders (ESEMeD) project. Acta Psychiatr Scand. 2004;109:21-7. http://dx.doi.org/10.1111/j.16000047.2004.00327.x.

38. Simon RW. Revisiting the relationships among gender, marital status, and mental health. AJS. 2002;107:1065-96.

39. Andersen I, Thielen K, Nygaard E, Diderichsen F. Social inequality in the prevalence of depressive disorders. J Epidemiol Community Health. 2009;63:575-81. http://dx.doi. org/10.1136/jech.2008.082719.

40. Snijders TAB. Fixed and random effects. In: Everitt B, Howell D, editors. Encyclopedia of Statistics in Behavioral Science. Chichester: Wiley; 2005. p. 664-5.

41. Brown GW, Bifulco A, Andrews B. Self-esteem and depression - III. Aetiological issues. Soc Psychiatry Psychiatr Epidemiol. 1990;25:235-43. http://dx.doi.org/10.1007/BF00788644.

42. Kendler KS, Gardner CO, Prescott CA. Toward a comprehensive developmental model for major depression in men. Am J Psychiatry. 2006;163:115-24. http://dx.doi. org/10.1176/appi.ajp.163.1.115.

43. Kendler KS, Gardner CO, Prescott CA. Toward a comprehensive developmental model for major depression in women. Am J Psychiatry. 2002;159:1133-45. http://dx.doi. org/10.1176/appi.ajp.159.7.1133.

44. Fayers PM, Machin D. Quality of life: assessment, analysis and interpretation. Chichester: John Wiley \& Sons; 2000. http:// dx.doi.org/10.1002/0470846283.

45. Podsakoff PM, MacKenzie SB, Jeong-Yeon L, Podsakoff NP. Common method biases in behavioral research: a critical review of the literature and recommended remedies. J Appl Psychol. 2003;88:879-903. http://dx.doi.org/10.1037/00219010.88.5.879.

46. Kolstad HA, Hansen Å, Kærgaard A, Thomsen JF, Kaerlev L, Mikkelsen S, et al. Job strain and the risk of depression: is reporting biased? Am J Epidemiol. 2011;173:94-102. http:// dx.doi.org/10.1093/aje/kwq318.

Received for publication: 10 January 2014 